\title{
THE AGENCY ROLE OF SD MODELS IN MODEL-BUILDING GROUPS
}

\author{
Dr. Maria Kapsali \\ Manchester Metropolitan University \\ Manchester Metropolitan University Business \\ School \\ Manchester, M15 6BH \\ UK \\ m.kapsali@mmu.ac.uk
}

Prof. Sally Brailsford

University of Southampton

Southampton Business School

Southampton SO17 1BJ

UK

s.c.brailsford@ soton.ac.uk

\author{
Dr. Steffen Bayer \\ University of Southampton \\ Southampton Business School \\ Southampton SO17 1BJ \\ UK \\ s.c.bayer@soton.ac.uk
}

Dr. Tim Bolt

Saitama University

Faculty of Economics

255 Shimo-Okubo, Sakura-ku

Saitama 338-8570

Japan

tbolt@mail.saitama-u.ac.jp

\begin{abstract}
This paper examines the role of a simulation model being developed within a group model building process. The paper argues that the model can be conceptualized as a being an agent in a model building group which influences, shapes and challenges the thinking of the group members. The paper presents two case studies of group model building projects and shows how the agency of the model in differently composed groups.
\end{abstract}

Keywords: Systems Dynamics; technological agency; case-based reasoning; model-based reasoning; group model building

\section{INTRODUCTION}

Simulation artefacts such as System Dynamics (SD) models are conceptual integrators and instrumental learning tools and as such are important in complex problem-solving. They are also found to perform a social role, e.g. as boundary objects. It is not clear however if SD modelling is more than just a tool, but rather plays the role of an agent when humans interact with it: "Can an SD model be conceptualized as exerting agency in group-model building, by influencing the reasoning of the group members - and if so, how?"

The setting is the group-model building process. We examine evidence of the influence of SD models on the reasoning of groups in two in-depth case studies.

In the rest of the article, we first explore this argument looking at two literatures: (i) the roles of technical artefacts in temporary groups and projects; and (ii) the SD group-model building. In the Section on 'Research Design' we explain how we investigated technological agency. Two in-depth case studies are offered in the 'Discussion of Case findings' Section. Then we conclude with the contributing points of this investigation. 


\section{LITERATURE REVIEW}

\subsection{The roles of technical artefacts in temporary groups and projects}

Research in the field of temporary groups and projects consider the role of technological artefacts but has yielded diverse findings. One line of studies suggests that ICT artefacts cannot replace personal interaction (Sapsed and Salter, 2004) especially when there are too many interfaces (Hoegl et al., 2004) or when either interdependency is weak or knowledge creation and codification are complex (Brensen et al., 2004). A second line of studies advocates that technical artefacts 'enframe predictable and coordinated action' (Kallinikos, 2005: 199) supporting predictable interactions, or partially reflect and embody hierarchy (Eriksson-Zetterquist et al., 2009) or materialize the temporal structuring of routines (Orlikowski, 2007).

A third line of studies examines the social roles of technological artefacts as boundary objects. These roles refer to mediating between the group and the parent organisation (Garrety et al., 2004); aligning objectives and handling conflict, negotiations, creativity, and contracts (Koskinen and Makinen, 2009; Jensen et al., 2006; Alderman et al., 2005); integrating and codifying knowledge and symbolic value (Swan et al., 2007); and supporting learning (Yakura, 2002) and sense-making (Papadimitriou and Pellegrin, 2007). On the other hand, they can also serve to intensify tensions, divisions and information asymmetry and to assert roles, norms, identity, power or status within group relations (Dodgson et al., 2007; Carlile, 2002) reifying cultural boundaries (Barrett and Oborn, 2010).

Previous studies in temporary groups and projects addressing the roles of technological artefacts do not consider their agency (Chongthammakun and Jackson, 2012) and see them merely as carriers, representations or integrators of knowledge, meaning, learning and organizing (Ewenstein and Whyte, 2009).

\subsection{The process of group-model building}

Simulation building is usually envisaged as a linear-rational process with a series of logical steps. However, recent studies have revealed a slightly different picture. Tako (2008) and Tako and Robinson (2010) found that SD projects in particular, deviate slightly from this stereotype in these ways: because SD models are systemic (i.e. built on relationships and interactions within a system) and represent a social system as a whole, they are suitable for policy and strategic problems that are quite complex. In such a situation, SD modellers are compelled to consider the broader aspects of a problem in a more holistic pattern. SD group-model building is not linear, and the cyclicality of action is distinctive. SD modellers jump iteratively from conceptual modelling to coding or data input and then go back to modelling, etc. Causal relationships, dynamic complexity and feedback are important conversations in SD groups who need both quantitative and qualitative data to address them. SD modellers perform 'black-box' validation: this means checking both the numerical outcomes and the patterns of the qualitative results to validate the model and are keener to experiment with scenarios. Users find SD slightly more representative of the problem and instructive, but complex.

The SD model building process is divided into two phases. First phase is the construction of a shared conceptual frame (or the model structure). In the construction phase, a group identifies links from diverse stories and these links are used to build the model structure and to define the data that needs to be collected. In this phase, people exercise two types of reasoning: case-based and modelbased. Human sense-making and artefacts interact (Hernes and Maitlis, 2010: 31) and inductive (casebased) (Graham, Smith and Crapper, 2004) and abductive (model-based) reasoning (Develaki, 2017: 1003) may occur simultaneously or iteratively. Case-based reasoning happens when experiences of specific prior reasoning episodes are recalled and adapted to interpret a similar situation. Model-based reasoning happens when people correlate data in a model that can then be used to make sense of the "real world". In the reification phase, the SD consultants determine the equations describing the mathematical relationships, code the model in a simulation package or programming language and parameterise the model with data. Finally, they test different scenarios and validate the model.

The model building process can be problematic. Systems that are modelled are usually complex and problems are 'fuzzy' or ill-structured and the 'problem space' (Simon, 1978) is not well defined. Problem definition is the most important, intense, time-consuming and risky step in the construction 
phase (Cochran et al., 1995). A major challenge in achieving group consensus around the problem definition is the existence of priors, which are conceptual preconceptions, assumptions or expectations (Urban, 1974). During testing scenarios, models constrain the ways in which they can be interpreted (Knuuttila and Voutilainen, 2003), and they can produce results that collide with priors. A further difficulty stems from the need to decide how detailed or abstract the model structure should be (Urban, 1974). A complex model will often challenge human understanding. Major hindrances include the lack of familiarity with modelling, and the inability to think in abstract terms and to prioritize information from multiple sources (Cochran et al., 1995).

\section{RESEARCH DESIGN}

We studied the agency patterns of simulation artefacts, and we define SD agency here as the ability to challenge the perceptions of a diverse group of people, create a reaction and change their individual stories and mode of reasoning, in the two modelling phases. Our definition is influenced by the definition of the material effects of technologies as "tangible resources that provide people with the ability to do old things in new ways and to do things they could not do before" (Leonardi and Barley $2008,161)$. In this situation, we argue, the mode of reasoning is affected when the group members repeatedly confront the constraining and enabling features of the conceptual technology (technological agency; Jarrahi and Nelson, 2018). We therefore looked for evidence of how the SD model causes change in the type of reasoning (case vs. model) at any time during the group-model building project phases.

\subsection{Data collection}

We collected evidence from two group-modelling projects that both run over the course of one year, and we conducted ethnographic, secondary and in-depth interview methods. Firstly, by participating in the series of modelling workshops (eleven sessions in total), in which we observed how the groups worked. Secondly, by conducting interviews with the participants in both projects afterwards (an additional year), including clients, consultants and expert advisory members (seventeen interviews in total). We also collected their project documentation, including minutes of their meetings.

\subsection{Data analysis}

In examining the possible agency of models in group-model building, we adopted the approach of theory elaboration. Theory elaboration is conducted through qualitative analysis and depends on comparison; data from each case are used to refine concepts and then to compare the outcomes.

Our analysis was conducted in two steps. First, we used content analysis and comparative matrix analysis (Miles and Huberman, 1994) to identify how participants interacted with the SD model. Secondly, we mapped what happened in the phases to capture the roles and effects of the model.

\subsection{Context}

In theory, elaboration occurs simultaneously provided cases have been chosen: cases of similar phenomena with well-defined differences (Glaser and Strauss, 1967). Our comparative in-depth case design provides a strong foundation for elaborating theory (Bluhm et al., 2011) because the similarities between the cases allow for meaningful comparisons, and their differences provide a basis for discovering new themes. The groups we selected had two important similarities and one difference. First, both groups had similar heterogeneous consistency. The second similarity was that both groups had to tackle the same problem: to build a model that helps to develop interventions and policies to reduce hospital admissions due to the same type of health issue.

Group A consisted of twelve people from one locality, including a project manager organising the meetings and liaising with the client, a simulation consultant, a data manager and nine local group members. These included a commissioner at the local PCT, representatives of different NHS services (4 members) as well as of the local council ( 2 members) and from third-sector service providers (3 group members).The group met five times within a period of five months, during which observations were made by our team. Group B was charged with developing a simulation model for hospital admissions for use by PCTs across the country. Group B consisted of fourteen members, including a 
project manager and a simulation consultant. Of the twelve other group members, seven of the members worked at the Department of Health (DoH) and the National Health Service (NHS) in decision-making roles (clinical, statistics and policy), two were PCT commissioners and three were senior academics who were nationally recognised experts in the specific health-care area, one was from the third sector and one from the National Audit Office. The group met six times across six months, which we observed.

The difference between the groups was their prior experience. In the local group (A), the members worked in different parts of the local health-care system, mainly occupying operational or managerial positions, and therefore had a 'grass-roots' view of the service. In group B, the members worked in research, in academia, policymaking and $\mathrm{DoH}$; therefore they all had a 'helicopter' view of the problem and service.

\section{DISCUSSION OF CASE FINDINGS}

\subsection{Group A: from case to model-based reasoning}

The composition of group A shaped the model building process in three respects. First, most members were not familiar with modelling. Therefore, they did come to the project with expectations: 'we were more open-minded because we didn't know what to expect' (commissioner). Second, because members worked in different operational roles in different parts of the service, they had diverse perceptions of the problem based on their individual experiences. Some participants focused on public health measures and prevention while others cared mostly about service provision and treatment. The client's objective was the reduction in admissions. This was the first in a series of conflicts.

The members struggled with the fact that the problem was about reducing hospital admissions; eventually a more holistic point of view won them over, and they agreed to the "storyline" that preventive and treatment services are complementary: '... I think the link in with the different services was helpful because it allowed them to understand where we could action things from the front' (manager 1); '...I can see in the grand scheme of things where we do fit in' (manager 2). In addition, the majority of members had a shorter-term perspective in mind than the one needed for the problem set to them: '....what we're looking at there was a project that went well into the future' (manager 1).

During the construction process, the group members also disagreed about the definition of the concepts used: ' ... we did spend a lot of time talking about definitions of the stocks, key stocks in the model, and that was important because everybody had come in with different definitions about how best to define the groups of patients - there was a national definition which differed from the PCT definition and that was part of the debate ... there were two meetings, at least, before we determined what the stocks finally were ...' (consultant); '... the group had a different definition to every word that you could possibly come up with' (data manager). Because their backgrounds varied significantly, the members did not share common interpretations of the same issues. In addition, the discussion was mainly among NHS participants, while the third-sector service providers felt left out of this discussion: '... A lot of it went straight over my head, I'll have to admit because the things they talked about... I understood the principles of what they were saying but a lot of it... that the NHS are talking to each other so they understand what they're talking about ... NHS talk' (manager 2).

The diversity of group members' positions was a challenge to unite these fragmentary snippets and abstract the "bigger picture": '...., they were little in the big picture. They had their views and were based on personal experience rather than on proven science' (commissioner). The group members mistrusted more abstract and conceptual explanations and they insisted that the model structure should be made more detailed. Therefore, the consultant decided to adopt an inductive casebased approach to construct the model structure from details in their narratives.

During the reification process, similar issues became visible. The members needed to find the data to parameterise the model and start testing it. There was a problem with finding available data sources, and the data were not complete, so this stage was protracted: '... it was difficult for me to sit there as a local manager trying to link in your facts and figures with our facts and figures, because I didn't have those figures in hand' (manager 4). Some of the data was less robust: 'That research basically sat on one of the clipboards in one hospital ten years ago...' (commissioner) - so there was 
doubt about the accuracy of the model as a representation of what really happens. This doubt made the members sceptical, reinforced their disbelief in the abstract view of modelling. However, chasing data made them keep asking questions, and they continued in cycles, immersing into a re-examination of definitions as they tried to distil a coherent story '... I think that's why we learnt so much because we had to keep on looking for data ...' (PCT manager). By this time, the group started to see a shared story, even if they acknowledged that this story might not be completely accurate, but at least plausible and coherent, which encourage them revise their previous anecdotal beliefs.

The group members also encountered a series of 'surprises' that challenged their prior beliefs. It was both a confusing and illuminating turning point for the members when experiments shocked their assumptions. The model started to have a voice, it was as if it kept on saying to them to not only look for data, but also to re-think how the system works and which interventions mattered. Some people started to feel that they did not really know the answers anymore, '... they thought oh, actually not, maybe our assumptions were wrong, and they later changed their approach,' (PCT manager), and started asking themselves why '...there was a little bit of why, because when we could see that, the effects of some of the things which we may have logically thought would have had an effect, didn't, or because something else did at some point' (data manager). This was a recursive process: as they used more case based reasoning they changed the model, which in turn gave them results they did not expect, triggering more model based analysis: '... I saw their understanding change the resource for certain things. They obviously see how it changed the model ...' (manager 2). An interesting dialogue emerged in which people were speculating in terms of what the model would say in response to their explanations: in this "dialogue" the model triggered a change in the way people made sense.'

The first surprise was when they confronted the fact that the service is more complex than they originally thought. Reflecting on this experience, one participant considered 'Is it the fact that it highlighted that actually it's a lot more complicated than what we think? You know, we think... working in this field, we think it's quite simple' (manager 3). Initially some had questioned the value of modelling for what they perceived to be a simple system '... I can see them working on this sort of work with, you know, like BP and British Airways. Do you know what I mean? I can see that, but for the town, this little process of getting people into treatment services isn't that complicated...' (manager 4). This prior expectation was challenged when members saw that patients go in and out of remission and therefore go into cycles within the service, mixing across pathways that were initially presumed to be linear. The consultant used the analogy of the road network to describe the phenomenon: '... It surprised me, so then it would surprise them even more, ... you tend to stay within a cycle. It's very, very difficult to get out of it completely. The only way out of that true cycle is to die...' (data manager). This insight of the complex nature of the issues generated a lot of discussion on '... where they were, what they were doing and what needed to be done' (manager 5).

The second surprise was whether prevention or treatment services would have a greater impact on admissions. The model challenged the presumption that established treatment services were effective. The model showed that the key intervention that could work long-term to reduce admissions of chronic patients was a public health measure: '... when people started to see the effect when changing some of the parameters, some of the things you might have expected to make a huge difference might have made a difference in the beginning but then levelled out. I was very sceptical about the whole thing, but when the model showed what the effect was, it was quite surprising to me to see that' (data manager); 'We looked at a whole range of interventions, both proactive and reactive, ... and nothing really made too much difference. That was another thing that was worth learning, actually ....' and '.... they got out of that the single most effective thing they could do is (identified specific policy intervention). ... There's quite a bit of resistance to that theory.' (consultant). Naturally, there was much resistance to this revelation. Interventions that were taken for granted to be effective suddenly did not seem to work.

The third surprise caused strong arguments because the model highlighted the importance of the chronic, long-term side of the condition as the main cause of admissions. Previously all the group members believed the cause to be short-term, acute issues. The model changed their stories - and led them to think in a model-based way instead of trusting only their prior cases.

The effects of the experiments were so dramatic that group members questioned again the accuracy of the model structure and the adequacy of the data. Whenever they saw surprising results, 
they went back to almost the beginning to redefine parts of the model structure: '...understandings were actually growing because each time they put forward ideas... they went back to almost the beginning on a lot of occasions, you know...' (manager). In the final analysis, many of the participants understood the value of model-based abstraction; the truth in the model lies in the way of perceiving the service, not in the results: '... It is not so much an accurate tool but a way to think about things - projecting...' (manager 1). This iterative process, changed the way they made sense: '... but the most useful part of the whole process wasn't what we had at the end, it was the conversations we had along the way and the extra research it made us go out to do to find out answers to questions and ask more questions along the way, helped everybody understand it a lot more. Every time you come up with an answer, you end up with another question, which is good for research' (PCT manager).

In the final presentation to the senior management in the client, the model surprised them as well. However, because the Board members did not participate in the process, so the model had no effect as an agent on their priors and reasoning: '... Because the slides were demonstrating there was a weakness in an area and she (senior manager) was saying, no, we've invested quite a lot of money in here and that those figures can't be right. I don't think the presentation captivated their attention enough' (manager 3). The senior management questioned the validity of the model.

\subsection{Group B: from model to case-based reasoning}

Most of the policy, academic and NHS people in group B were acquainted with each other's work and had interacted previously (e.g., through conferences). Most of the group members had a broad overview of the relevant issues and deep knowledge of scientific evidence around different interventions: '...you know, it's something we've spent our lives thinking about' (clinician). In addition, many had previous experience in modelling the health service using other types of tools. They all had an abstract, 'helicopter' view of the service in question. The modelling consultants felt that a more model-based approach was appropriate for this group because there was a broad consensus already about the system and underlying concepts and data was available to or even known by the participants.

Despite their common ground, there was nevertheless disagreement regarding the problem definition: '.. the debate was about the brief, not about the model' (consultant). Their disagreement was whether the model should use hospital admissions as the outcome measure. It was difficult for them to set priorities because the policy agenda was ambiguous: '... the problem probably was the case that this is still an emerging piece of work; a lot of hard work has gone into developing the objective so far, but it is still developing ....' (consultant). An important factor was the complexity of NHS and the transition towards a system with more private provision: '... So, I think there are problems because we don't really know what sort of healthcare system we've got at the moment. We seem to be, you know, in this transition from the NHS as we all knew it, and a new kind of private sector, or at the moment it's a sort of quasi private sector with the doctors management trying to article over the cracks, I think' (lead clinician).

The construction phase started on model based reasoning. First, consultants sketched an initial model structure. They narrowed down the structure to fit the service. However, '... narrowing the scope just to the NHS service did not paint the full picture of what other services in the rest of the system can contribute' (policy analyst). There were objections to this process by academics and clinicians who thought that the process should be more exploratory and that this approach resulted in an explanation that was too linear and too simplistic. Others expected a fast process that would produce a forecasting tool for commissioners and also disagreed with the deductive process: '....start with a simpler explanation rather than the more complex to the simple' (economic advisor). Some thought '...that the group understanding of the modelling process, and the group's input at discussion was out of sync' (clinician). The objectives of the group became contentious in the construction phase prolonging it; such that it took three or four meetings to come up with a final model structure.

The model structure produced was highly abstract. Initial simulation experiments predicted costs which seemed excessive to the group members. For this reason, they did not trust the model and assumed it was overly simplistic. They then decided to alter the model structure and to disaggregate some of the services through testing. 
During reification, several data issues emerged. While the group had access to databases from the DoH and academic research, some of the data was based on limited evidence or not available on a local level, or inconsistent throughout the country. This lack of robust data raised questions: 'does the data exist; is the data correct; is the data suitable; is the data utilised properly' (statistician DoH).

Questioning the data led to much creativity during reification and, generally, this group was experimenting with the model very actively. During experimentation, the participants faced the fact that the model commanded mental discipline constraining certain ways of thinking. One participant described this as the model exerting a 'gravitational force because of the focus it commands', although 'sometimes the focus on building the model overshadows the effort to learn' (academic). Most group members found experimenting with the model stimulating: '... people would physically get up off the table and sort of go and point at the screen and say you know, "why?" (consultant). Testing was '... Absolutely fantastic! It was an eye opener to me anyway ... useful in understanding the consequences of potential policies' (clinician) - '... Yes, yes, yes, most definitely, most definitely. I think being allowed to play with ideas, to play with sort of 'Monopoly' money if you like, well you know... It is primarily a creative tool' (economic advisor) - '...Yeah absolutely, it's the ultimate "flight simulator" for the public sector; you have a risk-free environment in which to play out policy changes and see whether the indications are going to work' (associate). Some members arranged individual meetings with the consultants to obtain more guidance for testing the model by themselves.

This is the point where people used scenarios from their own experience (case-based). They had to '... choose evidence, challenge it and make extrapolations from it '(academic); they had to challenge and let go of what they thought they knew. It was enjoyable for most and created new surprising insights. A surprising insight was to discover which services were actually the most expensive. This discovery 'created a shift, and people directed the shift within the model' (commissioner 1). After the experiments they tweaked the model structure and participants gained more confidence: '... I felt reasonably comfortable, primarily because... what was coming out the work made intuitive sense, and so from a purely sense-check perspective, you know, it held true ...' (DoH statistician). It took two months to digest what the model was saying about the treatment, but during this time, the model generated a lot of discussion and a lot of curiosity. Although it was difficult to structure initially, the model helped them to think in a more sophisticated way: '... it's about helping people be more sophisticated about the treatments...' (policy analyst).

The members of this group seemed more comfortable when the model surprised them disputing their priors. They responded by adopting a more case-based approach in the reification phase. They also faced new questions regarding how to convey these messages to local NHS organisations. However, the members were satisfied that the model provided a focus towards the right changes in commissioning and that the model added to the body of knowledge instead of just implementing it. Most importantly, people understood that problem solving is not about using a forecasting tool that provides estimates but, rather, the way they perceived a complex system.

\section{CONCLUSIONS: THE ROLE OF THE SD MODEL AS AN AGENT}

Regarding our initial question: "Can an SD model be conceptualized as exerting agency in groupmodel building, by influencing the reasoning of the group members - and if so, how?" the answer is that we observed in these groups that the SD model did exert this influence. The artefact changed the type of reasoning that prevailed in each group (from case to model reasoning and vice versa) when they enacted with the model.

Regarding the way this happened, we observed that the agency of the SD model influenced the reasoning of the groups through a series of 'shocks' or surprises that were resisted initially by the groups. When the first round of testing did not provide expected results, both groups changed the initial model structure until during experimentation they finally felt comfortable using a different type of reasoning. Therefore, conflict of expectations with model experimentation is the point where the artefact changed the mode of reasoning of group members and became an agent. When their expectations got out of the way, their stories changed. During this process, the model changed the way in which they made sense of the problem and how they understood the healthcare service.

These shocks or surprises activated the SD model as an agent. We saw that the artefact had an active role by enabling the groups to rethink events, agents, goals, ideas and results together in a 
relational and temporal sequence. We saw how the model questioned definitions about the problem and assumptions about the system and the reliability of people's stories through constraining their assumptions (Jarrahi and Nelson, 2018). The model imposed its own syntax and constrains on the process of learning and exploration, but it also broadened a more holistic view of the problem by forcing people to ask questions they would not before, think in alternative ways and make sense of elements that they had not considered (Leonardi and Barley 2008). The model was not just a medium but became an agent in creating these messages, responding to ideas and initiating these conversations. Therefore, we saw how the SD model brought the fragmented stories together.

Finally, we observed that people who did not participate in the model building process and did not have the experience of interacting with the model and trained to think differently, were not able to accept and comprehend its results. However, this does not in itself mean that the model was embodying the "truth" which non-participants could not understand. Indeed, it might be the case that the insights the participants gained from the model were misleading and that doubts about the accuracy of the model were appropriate. Our study as a study of the modelling process needs to be agnostic in regards to this question - we saw that the model changed the understanding the beliefs participants had about the reality and helped them to integrate different pieces of information and knowledge held by different stakeholders. We could observe that the participation in the modelling process led to the consideration of additional information and that the results were in the main judged to be convincing by those involved, but a scientific assessment of the accuracy of the model would require a different type study; a study of the process of modelling and the role of the model in this process cannot arrive at conclusions about the accuracy of the model. What we can conclude is that simulation models can be conceptualized as agents in group model building processes where the group is tasked with analysing complex systems. The model as artefact changes how group participants deal with ill-structured, fuzzy problems and a diverse array of confusing information and how they gain confidence in their (model derived) understanding.

\section{REFERENCES}

Alderman, N., Ivory, C., McLoughlin, I. and Vaughan, R. (2005). Sense-making as a process within complex service projects. International Journal of Project Management 23: pp 380-385.

Barrett, M, and Oborn, E. (2010). Boundary object use in cross-cultural software development teams. Human Relations 63(8): pp 1199-1221.

Bluhm, D. J., Harman, W., Lee, T. W., and Mitchell, T. R. (2011). Qualitative Research in Management: A Decade of Progress. Journal of Management Studies 48: pp 1866-1891.

Blumer, H. (1969). Symbolic interactionism: perspective and method. NJ: Prentice-Hall.

Bresnen, M., Goussevskaia, A., and Swan, J. (2004). Embedding New Management Knowledge in Project-Based Organizations. Organization Studies 25: pp 1535-1555.

Carlile, P. R. (2002). A Pragmatic View of Knowledge and Boundaries: Boundary Objects in New Product Development. Organization Science 13(4): pp 442-455.

Chongthammakun, R., and Jackson, S. J. (2012, January). Boundary objects, agents, and organizations: Lessons from e-document system development in Thailand. In 2012 45th Hawaii International Conference on System Sciences, (pp 2249-2258). IEEE.

Cochran, J. K., Mackulak, G. T., and Savory, P. A. (1995). Simulation Project Characteristics in Industrial Settings. Interfaces 25: pp 104-113.

Dodgson, M,. Gann, D., and Salter, A. (2007). The impact of modelling and simulation on engineering problem solving. Technology Analysis Strategic Management 19(4): pp 471-489.

Eriksson-Zetterquist, U., Lindberg, K., and Styhre, A. (2009). When the good times are over: Professionals encountering new technology. Human Relations 62: pp 1145-1170.

Ewenstein, B., and Whyte, J. (2009). Knowledge practices in design: The role of visual representations as 'Epistemic objects. Organization Studies 30(1), pp 7-30.

Garrety, K., Robertson, P. L., Badham, R. (2004). Integrating communities of practice in technology development projects. International Journal of Project Management 22: pp 351-358.

Glaser, B. G., and Strauss, A. L. (1967). The discovery of grounded theory: strategies of qualitative research. New York: Aldine. 
Graham, D., Smith, S. D. and Crapper, M. (2004). Improving concrete placement simulation with a case-based reasoning input. Civil Engineering and Environmental Systems 21(2): pp 137-150.

Hernes, T., and Maitlis, S. (2010). Process, sensemaking, and organizing. Oxford: OUP.

Hoegl, M., Weinkauf, K., and Gemuenden, H. G. (2004). Inter-team Coordination, Project Commitment, and Teamwork in Multi-team RandD Projects: A Longitudinal Study. Organization Science 15: pp 38-55.

Hovmand, P. (2014). Community Based System Dynamics, Springer, 2014.

Jarrahi, M. H., and Nelson, S. B. (2018). Agency, sociomateriality, and configuration work. The Information Society 34(4): pp 244-260.

Jensen, C., Johansson, S., and Lofstrom, M. (2006). Project relationships - A model for analyzing interactional uncertainty. International Journal of Project Management 24, pp 4-12.

Kallinikos, J (2005). The Order of Technology: Complexity and Control in a Connected World. Information and Organization 15(3): pp 185-202.

Knuuttila, T., and Voutilainen, A. (2003). A Parser as an Epistemic Artefact: A Material View on Models. Philosophy of Science 70(5): pp 1484-1495.

Koskinen, K. U., and Makinen, S. (2009). Role of boundary objects in negotiations of project contracts. International Journal of Project Management 27: pp 31-38.

Leonardi, P. M., and Barley. S. R. (2008). Materiality and change: Challenges to building better theory about technology and organizing. Information and Organization 18 (3): pp 159-76.

Maitlis, S. (2005). The Social Processes of Organizational Sensemaking. The Academy of Management Journal 48: pp 21-49.

Orlikowski, W. J. (2007). Sociomaterial practices: exploring technology at work. Organization Studies 28: pp 1435-1448.

Papadimitriou, K., and Pellegrin, C. (2007). Dynamics of a project through Intermediary Objects of Design (IODs): A sensemaking perspective. International Journal of Project Management 25: pp 437-445.

Simon, H. A. (1978). Rationality as Process and as Product of Thought. The American Economic Review 68: pp 1-16.

Sapsed, J., and Salter, A. (2004). Postcards from the edge: local communities, global programs and boundary objects. Organization Studies 25: pp 1515-1534.

Swan, J., Bresnen, M., Newell, S., and Robertson, M. (2007). The object of knowledge: the role of objects in biomedical innovation. Human Relations 60(12): pp 1809-1837.

Tako, A. A., and Robinson, S. (2010). Model development in discrete-event simulation and system dynamics: An empirical study of expert modellers. European Journal of Operational Research 207(2): pp 784-794.

Tako, A. A. (2008). Development and use of simulation models in Operational Research: a comparison of discrete-event simulation and system dynamics (Doctor of Philosophy), University of Warwick Retrieved from University of Warwick institutional repository: http://go.warwick.ac.uk/wrap/2984

Urban, G. L. (1974). Building Models for Decision Makers. Interfaces 4, 1-11.

Yakura, E. K. (2002). Charting time: Timelines as temporal boundary objects. Academy of Management Journal 45(5): pp 956-970.

\section{AUTHOR BIOGRAPHIES}

MARIA KAPSALI is a senior lecturer in the Business School, Manchester Metropolitan University. Previously, she was a Lecturer in Management Systems (specializing in Project/Operations Management) at Hull University Business School, a researcher and lecturer at Umeå University and a research associate at Imperial College Business School. Her interest is in project management, in particular the coordination of groups of creatives in innovation projects from a socio-technical systems perspective.

STEFFEN BAYER is Lecturer in Business Analytics at the University of Southampton and Programme Leader of the MSc in Business Analytics and Finance. Previously, he worked as Assistant 
Professor in the Program in Health Services \& Systems Research at Duke-NUS Medical School in Singapore, as well as a research fellow at Imperial College London and at the University of Sussex. His main research interest is the planning of health services using simulation modelling. He uses a variety of approaches in his research including qualitative research, system dynamics and discrete event simulation.

SALLY BRAILSFORD is Professor of Management Science at the University of Southampton. Sally obtained a BSc in Mathematics and then worked for several years as a nurse in the NHS before obtaining an MSc and then a $\mathrm{PhD}$ in Operational Research from Southampton. Her research is in the area of healthcare simulation modelling: to evaluate treatments and screening programmes, or to redesign and improve service delivery.

TIM BOLT is an Associate Professor of Economics at Saitama University, having previously worked in the School of Management and the Faculty of Health Sciences at Southampton University. His research focuses on health economics, discrete choice experiments and stated preference valuation methods. 